\title{
Inspection of artificially built mechanical failures through innovative condition monitoring techniques
}

\author{
S.Seçkin EROL ${ }^{1}$, Cemal MERAN ${ }^{2 *}$ \\ ${ }^{1}$ Kilis 7 Aralık University, Faculty of Engineering-Architecture, Mechanical Engineering Dept., Kilis, 79000 Turkey \\ ${ }^{2, *}$ Pamukkale University, Faculty of Engineering, Mechanical Engineering Dept., Denizli, 20020, Turkey, Corresponding author: \\ cmeran@pau.edu.tr
}

\begin{abstract}
In this study, the factors influence on root causes of failure initiation are examined with the original test implementation and condition monitoring techniques are emphasized. In working toward this goal, the laboratory test setups and tests which have been created by international research bodies are examined and in order to practise a new research work, a unique test setup system and a test plan is built. In this target of the root cause failure detection, vibration data at radial direction and electrical consumption data are collected through the analysis by comparing two different condition monitoring techniques. In this research, fault detection in modeling fault conditions and vibration, electrical consumption measurement have been let us examination in depth. During the tests, data are collected simultaneously in vibration by four-channel Data Acquisition Card (DAC) and electrical consumption by Motor Condition Monitoring (MCM) system which are integrated with an computer system. Respect to the study results; vibration analysis in detection of defects has been judged to be more successful in comparison with electric consumption analysis under the test conditions in perspective of condition based predictive maintenanceIn the study, it is mentioned that detection of failure initiations at sensitive levels and importance of consequent results.
\end{abstract}

\section{Introduction}

In order to reduce the cost of unit products, various optimization methods, logistics, spare parts, work studies as well as six sigma, lean manufacturing techniques and many other methods are applied. In addition to these methods, innovative maintenance techniques can provide significant gains in unit product costs with the reduction of maintenance costs which is one of the main expenses of the enterprises

Diagnostic and prognostic definitions have been transferred from the medical field to the field of mechanical engineering, and these descriptions have become the symbols of ongoing maintenance technologies. Historically, the concept of Prognostic and Health Management (PHM) has been used for the first time in medicine. Medical prognostication has defined the course of the disease as the future, both as a predictor of natural course, and as a predictor of post-treatment course [1]. Prognostication, by the simplest definition, can be described as the ability to consistently make accurate predictions with the detection and visualization of the initial signs of component deterioration [1]. The future development of prognostic and health management will be mutually influenced and even more widespread across different fields outside of engineering [2].
The condition monitoring technique is based on the reading of the equipment sensor measurements, which are indicative of the processes of deterioration, and the identification of certain features and their understanding of the condition monitoring technique and equipment health [3].

Orhan et al. [4] investigated two looseness faults with vibration analysis on two outer rings on the bearings of the fan motors and pumps. When fault detection is performed, it is stated that the general vibration values may be misleading, and that the change in fundamental frequency and harmonics should be followed. In addition, vibration analysis of uncomplicated machines has revealed that unbalance, mechanical looseness and misalignment errors can be detected with precision.

Karacay and Akturk [5] investigated a system with angular contact bearings in operation first by testing the vibration phenomena of the inner ring, outer ring and rolling elements at different rotation speeds with vibration technique, while the bearings were healthy first. He mentioned that even if there is no flaw in the bearings, it gives a vibration response and that in the spectrum graph, the ball passes through the harmonic frequencies. Elbhbah and Jyoti [6] reported that imbalances and imperfections were successfully detected by vibration analysis. 
This study is similar in terms of studies in the literature, types of defects and selected detection methods; the sensitivity levels in the imperfections, the number of cycles tested, the electrical frequencies and the approach in the detection methods.

\section{Material and method}

The test system used in this study was inspired by the climatic fan in a cement plant. Test setup consists of AC induction motor, double suction radial fan, five-legged elastic coupling and frequency converter. The test setup is placed on a stable table made of steel material. The system as a whole is associated with a computer system in which the data acquisition card and the motor status monitoring system are integrated. Figure 1 shows schematic view of the test fixture.

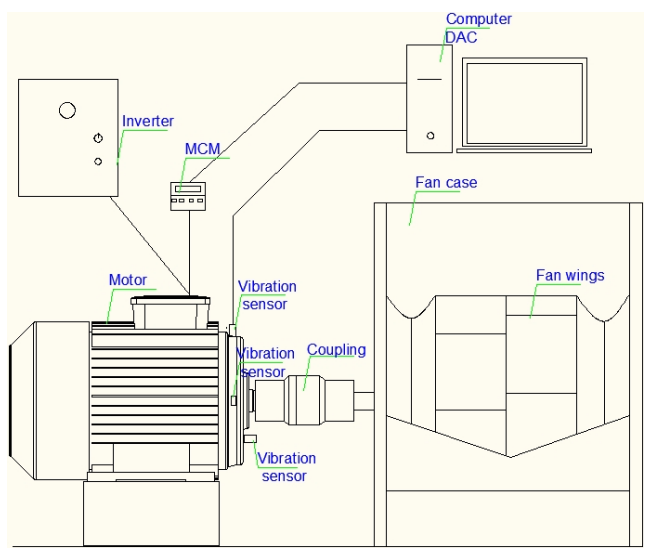

Fig. 1. Test rig

\subsection{Frequency harmonics and fault frequencies}

The approximate values of the theoretical (T) and actual (A) frequencies used in the tests are given in Table 1. While theoretical frequencies indicate the value digitally set on the frequency converter, the actual frequencies varying numerically by measuring some loss according to the data obtained during the application are measured.

Table 1. Harmonics in theory and actual; (f:frequency $(\mathrm{Hz})$; h: harmonics $(\mathrm{Hz})$ )

\begin{tabular}{|c|c|c|c|c|c|c|c|c|c|c|}
\hline (h) & \multicolumn{2}{|c|}{$\mathbf{1 x}$} & \multicolumn{2}{|c|}{$\mathbf{2 x}$} & \multicolumn{2}{|c|}{$3 \mathbf{x}$} & \multicolumn{2}{|c|}{$\mathbf{4 x}$} & \multicolumn{2}{|c|}{$\mathbf{5 x}$} \\
\cline { 2 - 10 } & & & & & & & & & & \\
(f) & $\mathbf{T}$ & $\mathbf{A}$ & $\mathbf{T}$ & $\mathbf{A}$ & $\mathbf{T}$ & $\mathbf{A}$ & $\mathbf{T}$ & $\mathbf{A}$ & $\mathbf{T}$ & $\mathbf{A}$ \\
\hline $\mathbf{5 0}$ & 50 & 47.61 & 100 & 95.22 & 150 & 142.83 & 200 & 190.44 & 250 & 238.05 \\
\hline
\end{tabular}

During the measurements in the tests, the rotational speed was measured as $2880 \mathrm{~min}^{-1}$ at the electricity frequency of $50 \mathrm{~Hz}$. Bearing and fan-induced vibrations are included in the calculations while calculating possible failure frequencies and harmonics of the test set.

The basic failure frequencies of the ORS 6202 bearing are calculated and presented in Table 2 .

Table 2. Main fault frequencies

\begin{tabular}{|c|c|c|c|c|c|c|}
\hline $\begin{array}{c}\mathrm{f} \\
(\mathrm{Hz})\end{array}$ & $\begin{array}{c}\omega_{\mathrm{s}} \\
(\mathrm{Hz})\end{array}$ & $\begin{array}{c}\omega_{\text {bpf }} \\
(\mathrm{Hz})\end{array}$ & $\begin{array}{c}\omega_{\mathrm{c}} \\
(\mathrm{Hz})\end{array}$ & $\begin{array}{c}\omega_{\text {bpfo }} \\
(\mathrm{Hz})\end{array}$ & $\begin{array}{c}\omega_{\text {bpfi }} \\
(\mathrm{Hz})\end{array}$ & $\begin{array}{c}\omega_{\text {bsf }} \\
(\mathrm{Hz})\end{array}$ \\
\hline 50 & 47.61 & 476.1 & 19 & 152 & 248 & 98.16 \\
\hline
\end{tabular}

The electrical measurements carried out with the motor condition monitoring system that allows detection of defects by following current and voltage changes. Changes can be tracked on trend charts. The types of defects can be selected in trend graph and the changes can be displayed according to standard deviation and time.

\subsection{Test parameters}

In order to be able to determine the efficiency of the measurement techniques and to increase the sensitivity of the changes in the data obtained from the measurements, an electric motor with a low power of $0.37 \mathrm{~kW}$ is preferred to minimize the vibration and electrical consumption values.

Axis eruptive effect was investigated in the range of 0.1 $\mathrm{mm}-0.5 \mathrm{~mm}$ with a sensitivity of $0.1 \mathrm{~mm}$. The effect of the change in rotation on these defects was tested at $2880 \mathrm{~min}^{-1}$ revolutions per minute at the electricity frequency of $50 \mathrm{~Hz}$.

\section{Test findings}

The test findings were examined in two main titles, vibration data and electricity consumption data, in accordance with the aim of the study.

\subsection{Vibration Data and Analysis}

Five spectral signals with the highest amplitude in the spectrum charts and RMS values are presented for comparison. For this study, natural frequency data were collected from the motor, motor shaft, coupling, fan, fan shaft, sheet metal, test setup stand and floor where test setup is positioned, using the impact test with a plastic tipped hammer while the system was in motion. Natural frequencies are expressed as $f_{n}$.

* The radial direction after this part of operation is expressed only for the vertical direction.

\subsubsection{Tests of axial misalignment}

Tests are implemented at $2880 \mathrm{~min}^{-1}$ revolutions per minute $(\mathrm{rpm})$. As a result of the tests; as the level of axis 
misalignment increases, there is a higher amplitude increase in the axis misalignment indication signals compared to other signals. Waveform and spectrum findings are given for $0.2 \mathrm{~mm}$ and $0.5 \mathrm{~mm}$ levels; waterfall spectral data are given broader covering the range of $0.1 \mathrm{~mm}-0.5 \mathrm{~mm}$.

a) Test of axial misalignment at $0,2 \mathrm{~mm}$

When the radial direction vibration data are examined, the superharmonic resonance condition at the natural frequency of $96.44 \mathrm{~Hz}$, which is caused by the $95.21 \mathrm{~Hz}$ (2x) vibration signal is observed and detected as the most dominant signal. In Fig. 2, the radial direction have been found corresponding to the $2 \mathrm{x}$ misalignment harmonics and the natural frequency signals of the $51 \times \omega_{c}$ belongs to cage harmonic.

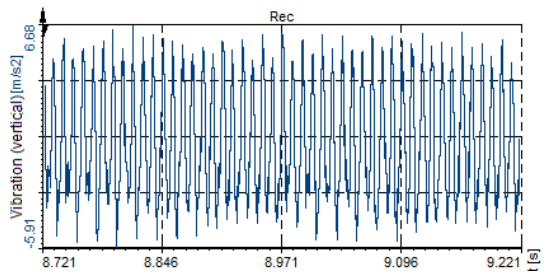

(a) Waveform graphic in radial direction

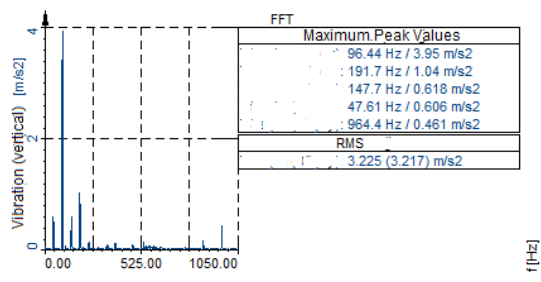

(b) Spectrum graphic in radial direction

Fig. 2. Axial misalignment data of $0.2 \mathrm{~mm}$

In the radial direction, the other vibration signals according to the dominance order are $191.7 \mathrm{~Hz}\left(f_{n}\right)$, $147.7 \mathrm{~Hz}\left(f_{n}\right), 47.61 \mathrm{~Hz}(1 \mathrm{x}), 964.4 \mathrm{~Hz}\left(f_{n}\right)$. It was observed 1x more dominant as the unbalance harmonic. Only fluctuation effect is observed in waveform graphs. In the radial direction, the signal at natural frequency of $96.44 \mathrm{~Hz}$ with the frequency of $95.21 \mathrm{~Hz}(2 \mathrm{x})$, the natural frequency of $191.7 \mathrm{~Hz}$ with the frequency of $190.44 \mathrm{~Hz}(4 \mathrm{x})$, the frequency of $142.83 \mathrm{~Hz}(3 \mathrm{x})$ with the natural frequency of $147.7 \mathrm{~Hz}$ is coincided and the superharmonic resonance condition has occurred.

\section{b) Test of axial misalignment at $0,5 \mathrm{~mm}$}

In Figure 3, the superharmonic resonance effect at the natural frequency of $96.44 \mathrm{~Hz}$, which is caused by the vibration signal at the frequency of $95.21 \mathrm{~Hz}(2 \mathrm{x})$, is detected as the most dominant signal at the radial direction.

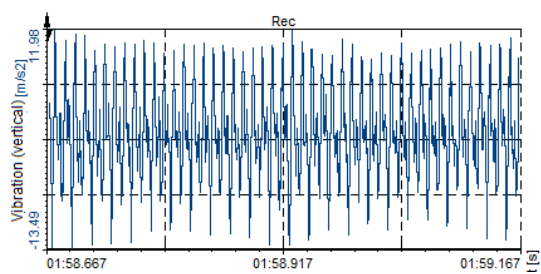

(a) Waveform graphic in radial direction

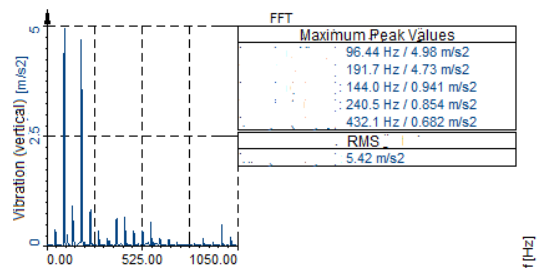

(b) Spectrum graphic in radial direction

Fig. 3. Axial misalignment data of $0.5 \mathrm{~mm}$

At the radial direction, the vibration signal at the frequency of $190.44 \mathrm{~Hz}(4 \mathrm{x})$ with the natural frequency of $191.7 \mathrm{~Hz}$, the vibration signal at the frequency of $240.5 \mathrm{~Hz}(5 \mathrm{x})$ with the natural frequency of $240.5 \mathrm{~Hz}$ and the vibration signal at the frequency of $428.49 \mathrm{~Hz}$ with the natural frequency of $432,1 \mathrm{~Hz}$ has caused superharmonic resonance by stimulating its natural frequency. Mechanical looseness harmonics have been observed over $3 \mathrm{x}$ and higher orders, including fundamental frequencies that stimulate natural frequencies, more pronounced in the radial direction.

In Table 3, radial harmonics are presented for comparison purposes.

Table 3. Axial misalignment signals at $2880 \mathrm{~min}^{-1}$

\begin{tabular}{|c|c|c|c|c|c|c|}
\hline MEASUREMENT & $1 . S$ & $2 . S$ & $3 . S$ & 4.S & $5 . \mathrm{S}$ & $\begin{array}{l}\text { RMS } \\
\left(\mathrm{m} / \mathbf{s}^{2}\right)\end{array}$ \\
\hline $\begin{array}{c}\mathrm{M} / 2880 \mathrm{~min}^{-1} / \\
0,2 \mathrm{~mm} /(\mathrm{R})\end{array}$ & $\begin{array}{c}f_{n} \\
(2 \mathrm{x})\end{array}$ & $\begin{array}{c}f_{n} \\
(4 \mathrm{x})\end{array}$ & $\begin{array}{c}f_{n} \\
(3 \mathrm{x})\end{array}$ & $1 \mathrm{x}$ & $\begin{array}{c}f_{n} \\
\left(51 \times \omega_{c}\right) \\
\end{array}$ & 3,217 \\
\hline $\begin{array}{c}\mathrm{M} / 2880 \mathrm{~min}^{-1} / \\
0,5 \mathrm{~mm} /(\mathrm{R})\end{array}$ & $\begin{array}{c}f_{n} \\
(2 \mathrm{x})\end{array}$ & $\begin{array}{c}f_{n} \\
(4 \mathrm{x}) \\
\end{array}$ & $\begin{array}{c}f_{n} \\
(3 \mathrm{x}) \\
\end{array}$ & $\begin{array}{c}f_{n} \\
(5 \mathrm{x})\end{array}$ & $\begin{array}{c}f_{n} \\
(9 \mathrm{x}) \\
\end{array}$ & 5,42 \\
\hline
\end{tabular}

M: Misalignment, R: Radial direction, S: Signal

According to Table 3, the natural frequency of the $2 \mathrm{x}$ misalignment harmonics is determined as the most dominant signal (1.S) in misalignment tests at $2880 \mathrm{~min}^{-1}$ revolutions whereas the natural frequency of the $4 \mathrm{x}$ mechanical looseness harmonics. The RMS values increased in parallel with the increase in the axial misalignment. In the radial direction, the two dominant first two signals $3 \mathrm{x}$ and $6 \mathrm{x}$ harmonics leave their place to the natural frequencies excited by the $2 x$ and $4 x$ harmonics. The misalignment spectrum changes at $2880 \mathrm{~min}^{-1}$ revolution are given in Fig 4. In graphs, there is a possibility of confusion with the mechanical looseness indication at the radial direction. 


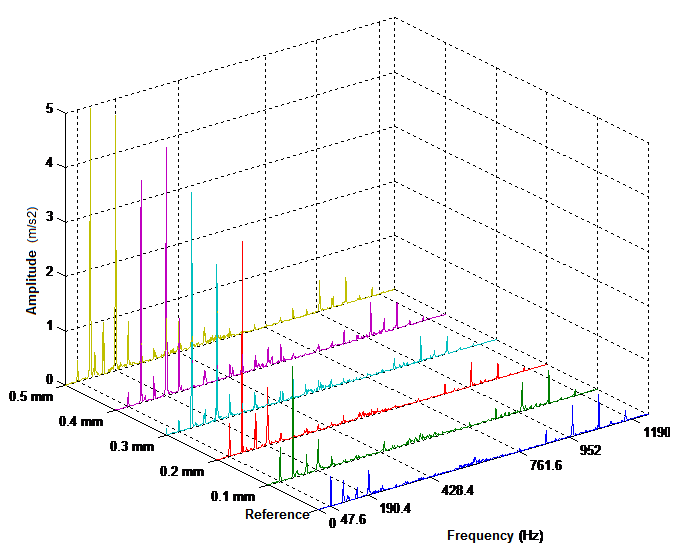

Fig. 4. Waterfall spectrum diagrams of axial misalignment

In Fig. 4, radial and axial direction vibration data at $2880 \mathrm{~min}^{-1} \mathrm{rpm}$ are given by waveform and spectral imaging techniques. $2 \mathrm{x}$ harmonics began to be evident when the axial misalignment level was in the range of $0.1 \mathrm{~mm}-0.2 \mathrm{~mm}$, and in the range of $0.3 \mathrm{~mm}-0.5 \mathrm{~mm}$, the signal amplitude became visible at the $4 \mathrm{x}$ harmonics as well as the $2 x$ harmonic. In the axial direction, only the signal amplitude increase at $2 \mathrm{x}$ harmonics becomes evident. Signals have begun to appear in the element transition region, being more pronounced in the radial direction.

\subsection{Electrical consumption data and analysis}

All the tests performed were evaluated by collecting data on the simultaneous consumption of electricity (current, voltage). The trend data is similar to the time-domain data, and the data can be analyzed as standard deviation respect to the selected parameters.

\subsubsection{Tests of axial misalignment with trend data}

Since the results are similar, no trend graph is given for all axis misalignment levels; given only for $0.2 \mathrm{~mm}$ and $0.5 \mathrm{~mm}$ levels. Variations in axial misalignment of $0.2 \mathrm{~mm}$ and $0.5 \mathrm{~mm}$ are given in Figure 5 .

Under the conditions of $0.2 \mathrm{~mm}$ misalignment, no indication of any failure was found in the tested speed.

Under the condition of $0.5 \mathrm{~mm}$ axis misalignment, there are some malfunctions in the test speed count. The number of revolutions at $2880 \mathrm{~min}^{-1}$ (f: $50 \mathrm{~Hz}$ ) speed level started to increase in loose ground / component, axial misalignment and bearing parameter values.

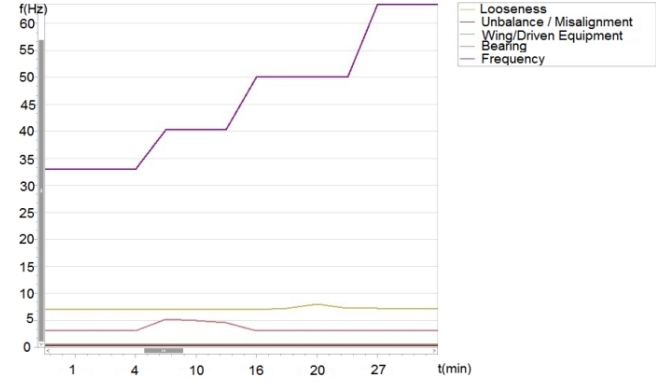

a) Trend data of axial misalignment at level of $0,2 \mathrm{~mm}$

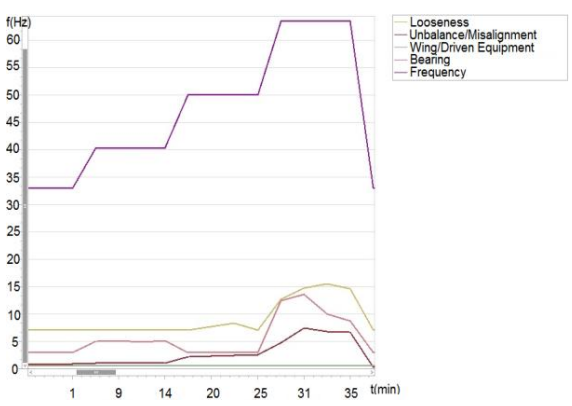

b) Trend data of axial misalignment at level of $0.5 \mathrm{~mm}$

Fig. 5. Trend data of axial misalignment at $0.2 \mathrm{~mm}$ and $0.5 \mathrm{~mm}$

\section{Conclusions}

In this study, two condition monitoring techniques based on vibration and electrical (current, voltage) consumption signals are studied. The results of the analyzes carried out on the basis of the obtained data are valid under the technical conditions under test. In these two condition monitoring techniques; vibration analysis results and trend analysis results of electricity consumption signals are not parallel. On the other hand, the vibration analysis technique was found to be more successful at the end of the study because expected results could not be obtained in the course of electrical trend analysis which is the main defect detection tool of Motor Condition Monitoring (MCM). Especially where vibration data collection is not possible, electrical consumption data can be evaluated; and also vibration analysis evaluations can be supported in the detection of electrical faults.

\section{Acknowledgment}

This study was supported by Pamukkale University Scientific Research Projects Coordination Unit with the project number 2012FBE010. 


\section{References}

1. Hess, A., Prognostics, From the Need to Reality- From the fleet users and PHM System Designer/Developers

Perspectives. Proceedings of the IEEE Aerospace Conference, BigSky, MT, USA., 6, 2791-2797, 2002.

2. Moubray, J., Reliability Centred Maintenance, 2nd edition, Butterworth-Heinemann Ltd., Great Britain, 2005.

3. Sudhar, G.N.D.S., Sekhar, A.S., Identification of unbalance in rotor bearing system, Journal of Sound and Vibration, 330, 2299-2313, 2011.

4. Orhan, S., Aktürk, N., ve Çelik, V., Vibration monitoring for defect diagnosis of rolling element bearings as a predictive maintenance tool: comprehensive case studies, NDT\&E International, 39, 293-298, 2006.

5. Karacay, T., Akturk, N., Experimental diagnostics of ball bearings using statistical and spectral methods, Tribology International, 42, 836-843, 2009.

6. Elbhbah, K., Jyoti, K.S., 2013: Vibration based condition monitoring of rotating machines using a machine composite spectrum, Journal of Sound and Vibration, 332, 2831-2845. 